\title{
Severe Hypothyroxinemia in a Young Adult with Carbimazole-Treated T3-Predominant Graves' Hyperthyroidism, Reversed with L-Thyroxine Loading Immediately Post-Total Thyroidectomy
}

\author{
Brenda Chiang ${ }^{1}$ and Yin Chian Kon ${ }^{2}$ \\ ${ }^{1}$ Department of General Medicine/Endocrinology, Sengkang General Hospital, Singapore \\ ${ }^{2}$ Department of Endocrinology, Tan Tock Seng Hospital, Singapore
}

\begin{abstract}
Patients with triiodothyronine (T3)-predominant Graves' hyperthyroidism with markedly elevated serum thyroid stimulating immunoglobulin (TSI) levels and massive goitre may display discordant hypothyroxinemia with eutriiodothyroninemia or hypertriiodothyroninemia while on anti-thyroid drug therapy. A 25-year-old female with the above was started on oral carbimazole therapy for 9 months before total thyroidectomy. Preoperatively, her serum free T4 was reduced to below detection limit, and total T4 reduced to $11 \%$ of lower limit of normal, while T3 levels remained normal, and TSH remained largely suppressed. Immediately after total-thyroidectomy, a loading dose of L-thyroxine (L-T4) was administered intravenously. She was extubated without any postoperative complications. Serum free and total T4, and TSH normalized within the next 24 hours. The peculiar thyroid axis dynamics and use of L-T4 postoperative loading in such a rare clinical scenario are discussed.
\end{abstract}

Key words: Graves' disease, hypothyroxinemia, T3-thyrotoxicosis, L-thyroxin

\section{INTRODUCTION}

Triiodothyronine (T3)-predominant Graves' disease was first described in 1984 and is defined by persistently elevated serum free T3 levels associated with hypothyroxinemia in Graves' disease patients who are on anti-thyroiddrug (ATD) therapy. ${ }^{1}$ It occurs in about $5 \%$ of Graves' thyrotoxic patients ${ }^{2}$ and is most often found in patients with higher thyroid stimulating immunoglobulin (TSI) levels together with larger thyroid glands that are iodine avid, have higher TPO activity and a lower thyroglobuliniodine content after treatment. ${ }^{3}$

\section{CASE}

Our patient is a 25-year-old, married female, who was diagnosed with Graves' disease at age 18 years. She had completed a 3-year course of carbimazole (CMZ) abroad, but suffered a relapse 6 months later, whereupon $C M Z$ was restarted by her doctor. Five months before presenting to us, her thyroid function was normal on CMZ $5 \mathrm{mg}$ every other day. She presented with $8 \mathrm{~kg}$ weight loss, palpitations and vomiting over the last 2 months, whilst compliant on low dose CMZ. She was not trying to conceive. On examination, she was alert with a GCS score of 15 . Her blood pressure was $131 / 79 \mathrm{mmHg}$, heart rate 135 beats/ min, regular. She weighed $40 \mathrm{~kg}$ and her body mass index was $17.5 . \mathrm{m}^{2}$. Her skin felt warm and sweaty, and she had fine tremors on outstretched hands. She had a WHO Grade 3 goitre, but signs of thyroid eye disease were absent. She denied any symptoms of dysphagia, difficulty breathing nor change in her voice. Her serum fT4 measured greater than $154.8 \mathrm{pmol} / \mathrm{L}$ (RR 8-21), fT3 greater than 30.8 pmol/L (RR 4.8-8.3) and thyroid stimulating hormone (TSH) $0.01 \mathrm{mIU} / \mathrm{L}$ (0.34-5.6). Her thyrotrophin receptor antibody (TRAb) level was greater than $40 \mathrm{IU} / \mathrm{L}(<1.0)$. Ultrasound thyroid scan revealed an enlarged thyroid gland with very heterogenous parenchyma and increased vascularity. The right lobe measured $10.9 \times 5.0 \times 5.5 \mathrm{~cm}$, left lobe $9.0 \times 5.0 \times 3.0 \mathrm{~cm}$ and isthmus $8.0 \times 3.7 \times 2.6 \mathrm{~cm}$. No thyroid nodules were seen on ultrasound.

Her dose of CMZ was increased to $100 \mathrm{mg}$ daily for a week then reduced to $30 \mathrm{mg}$ daily. The course of her weight, heart rate, thyroid function test (TFT) and CMZ daily dosage are depicted in Figures 1A to $C$ respectively. Over a span of 7 months, her serum TSH showed inappropriate suppressed or inappropriate normal levels when fT4 was low and T3 normal, as well as transient appropriate suppression due to T3 toxicosis (Figure 1B). She was advised to take appropriate contraceptive measures in view of her unstable TFTs, and scheduled for total thyroidectomy as definitive therapy for T3-predominant Graves' disease. She was well and clinically euthyroid on elective admission. Laboratory tests performed preoperatively showed serum free T4 less than $2 \mathrm{pmol} / \mathrm{L}(8-21)$, total T4 $10 \mathrm{nmo} / \mathrm{L}$ (70-140), free T3 $4.0 \mathrm{pmol} / \mathrm{L}$ (4.8-8.3), total T3 $2.07 \mathrm{nmol} / \mathrm{L}$ (0.9-2.6), TSH $16.9 \mathrm{mIU} / \mathrm{L}$ (0.34-5.6), TRAb $>40 \mathrm{IU} / \mathrm{L}(<1.0)$, and TSI $>5000 \%(<179)$. 

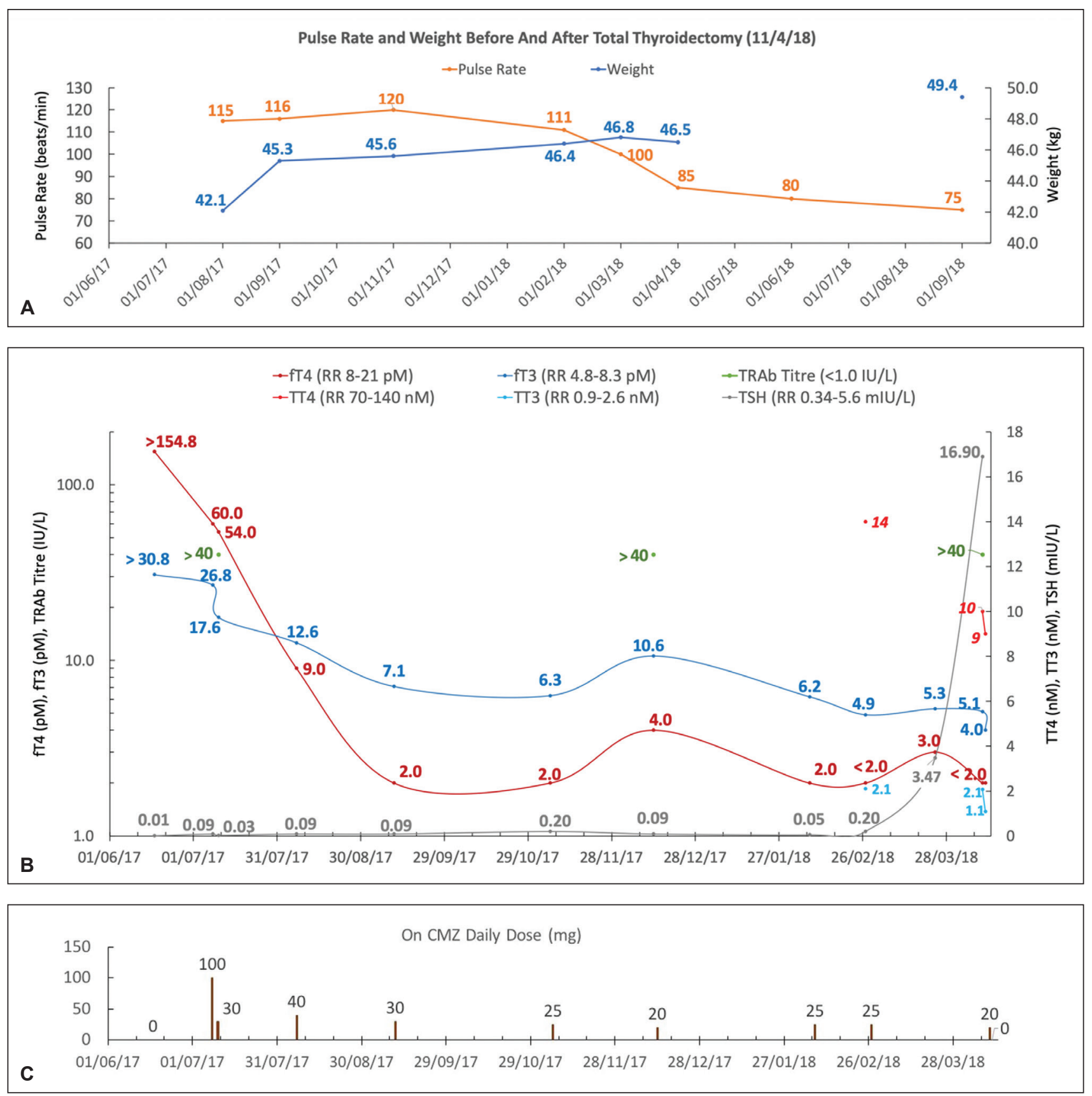

Figure 1. Serial (A) weight and heart rate; (B) thyroid function and TRAb titres and (C) daily dose of oral carbimazole (CMZ) therapy, in a patient with T3-predominant Graves' hyperthyroidism. TSH was suppressed from 11/9/17 to 6/11/17 (8 weeks with low fT4 and normal fT3), further suppressed on 13/12/17 (T3 toxicosis) and went from suppressed to normal from 7/2/18 to $24 / 3 / 18$ (6 weeks with low fT4 and normal T3).

In the operating theatre, immediately after her thyroid was excised, in view of her severely depleted total T4, intravenous L-thyroxine (L-T4) $500 \mathrm{mcg}$ (10 mcg/kg) was administered as a loading dose to quickly restore her circulating T4 reservoir. Her perioperative thyroid function tests in the first 24-hours post total-thyroidectomy are depicted in Figure 2. Post-operatively, there was no decreased ventilatory drive and she was extubated successfully. Other hypothyroid signs and symptoms were also absent. She was monitored closely for adverse effects such as cardiac ischaemia and infarction, tachycardia and palpitations. No immediate post-operative complications were observed. Her resected thyroid gland weighed 231 grams.
She was discharged well on the $3^{\text {rd }}$ postoperative day. She remained euthyroid (fT4 12-16 pmol/L, TSH 0.53$4.34 \mathrm{mIU} / \mathrm{L}$ ) on oral thyroxine replacement and conceived 21 months later. Her thyroxine dosage was optimized throughout pregnancy. Her TRAb levels had reduced to $3.2 \mathrm{IU} / \mathrm{L}$ at 34 weeks' gestation and she gave birth to a term healthy baby boy.

\section{DISCUSSION}

Normally, T4 and T3 are secreted by the thyroid in a ratio of 11:1, with the rest of circulating T3 produced extrathyroidally. ${ }^{4}$ In Graves' hyperthyroidism, there is an increase in the intrathyroidal deiodination of $\mathrm{T} 4$ to 


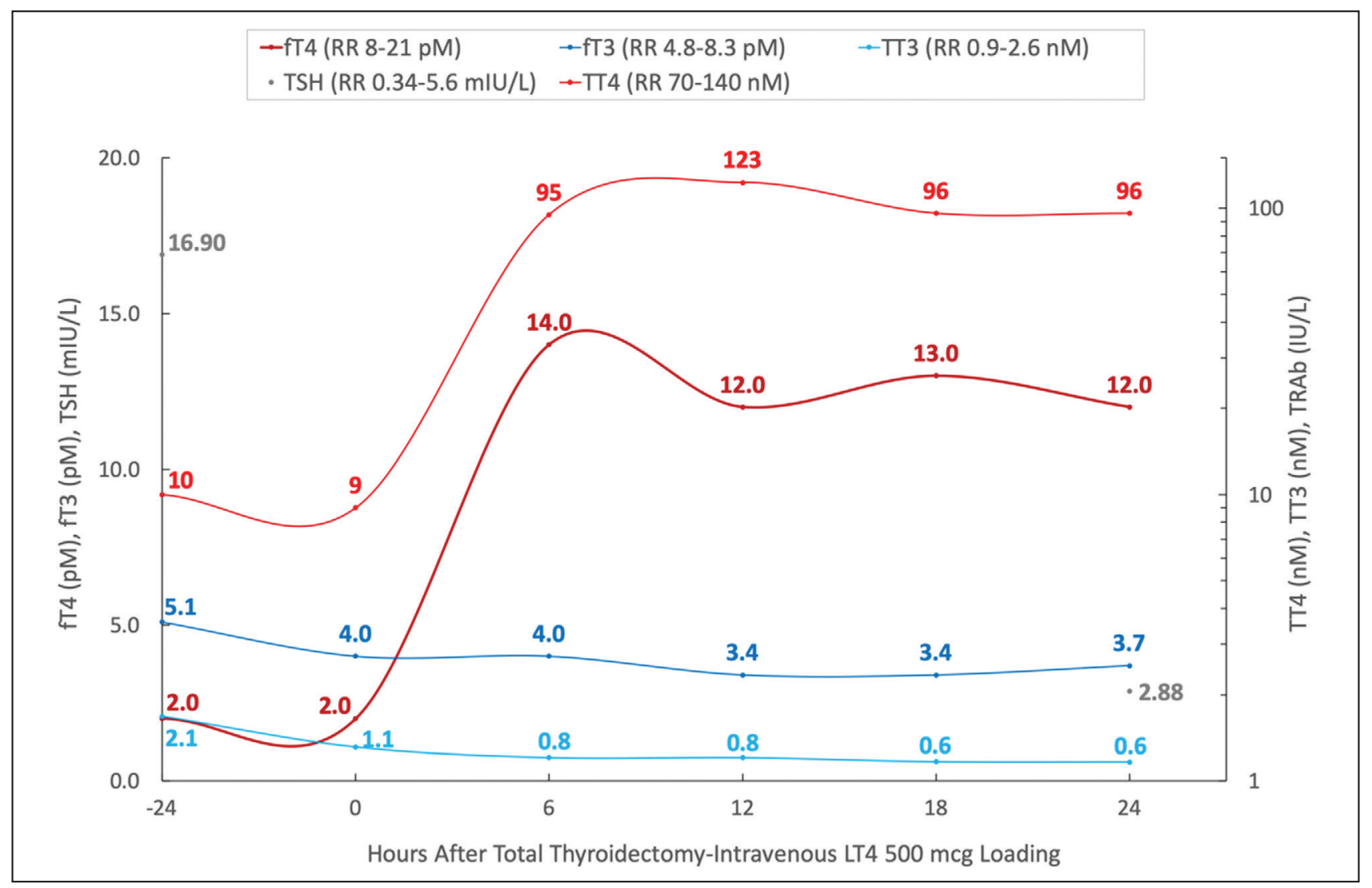

Figure 2. Thyroid function profile before and within 24-hours after total thyroidectomy with intravenous levothyroxine 500 mcg loading.

T3. ${ }^{5}$ The higher levels of TSI in T3-predominant Graves' disease result in greater stimulation and higher thyroid peroxidase (TPO) activity levels, higher iodine turnover and lower intrathyroidal iodine pool, and thus preferential T3 production. ${ }^{6}$

When serum fT4 is low and serum fT3 normal, hypothalamic-tancyte and pituitary-thyrotroph intracellular T3 levels should decrease, due to decreased availability of T4 for local conversion to T3 by type 2 iodothyronine deiodinase (DIO2) ${ }^{7-9}$ This should lead to an increase in serum TSH by negative feedback. In this case, serum TSH remained suppressed at times over a period of 24 weeks (Figure 1B). This is attributed to mild T3 toxicosis with delayed TSH recovery. However, it is speculated that besides driving high thyroidal iodine turnover, a high TRAb level may downregulate pituitary TSH secretion by an ultra-short negative feedback loop by acting on the pituitary TSH receptor (TSHR). ${ }^{10,11}$ The pituitary TSHR, expressed in the human anterior pituitary on folliculostellate cells, lies outside the blood-brain barrier and is therefore accessible to these autoantibodies. ${ }^{12}$ As the pituitary TSHR is also recognized by TSI, this interaction plausibly explains the prolonged serum TSH suppression despite serum fT4 being low and T3 being normal, until central regulatory tissue T3 levels were low enough to override the suppressive effect of TSI (Figure 1B). Chung et al.,'s retrospective study of Graves' patients on longterm ATD has provided some indirect evidence to support this hypothesis. They showed that after both T4 and T3 had been normal for 3, 6 and 12 months whilst on ATD therapy, serum TSH was inversely correlated with TRAb activities ( $\mathrm{r}=-0.353, p<0.001$ at 3 months; $-0.317,6$ months; and $-0.297,12$ months). ${ }^{13}$

High levels of TSI on concomitant ATD treatment leads to hypothyroxinemia with increased circulating $\mathrm{T} 3$ to T4 ratios due to intrathyroidal iodine depletion. ${ }^{1-3}$ The intriguing dynamics poses a therapeutic challenge to the clinician: should one aim to normalize TSH that would entail hypothyroxinemia, or target normal $\mathrm{T} 4$ that would entail T3 toxicosis (Figure 1B). In a seminal study by Pedraza et al., rats were rendered hypothyroxinemic to varying degrees by being fed different grades of iodinedeficient diets. When plasma total T4 was decreased to $25 \%$ of normal, plasma TSH had increased 6-fold, whereas plasma total T3 remained normal. When plasma total T4 was decreased to $5 \%$ of normal, plasma TSH had risen 10 -fold, and plasma total T3 reduced to $46 \%$ of normal. Intriguingly, tissue T3 levels were demonstrated to be tissue specific, being normal in muscle and heart, elevated in lung and ovary, but low in brain, pituitary and brown fat, in the same animal. ${ }^{14}$ Notably, tissues depending on plasma T3 would have normal T3 concentrations, while tissues that depend more on circulating $\mathrm{T} 4$ for the local generation of T3 would be less protected from hypothyroidism., ${ }^{9}$ Moreover, Fonseca et al., have elegantly shown in a DIO2knockout mouse model that the hypothalamic-thyroid axis is wired to maintain normal plasma T3 levels, through coordination of T4-to-T3 conversion between thyrotrophs and hypothalamus. ${ }^{15}$ Accordingly, we suggest that in the present clinical context, the priority target for ATD dose titration should be circulating fT3 level at upper normal. 
During early pregnancy, fetal brain development depends more on circulating maternal T4 than T3. ${ }^{16}$ When maternal serum T4 levels are low and T3 levels are normal or high, as seen in this case or when a patient is taking T3 supplements, fetal brain development might be adversely affected. Conversely, treating to high normal maternal fT4 levels to avoid ATD-induced fetal hypothyroidism would entail prolonged maternal T3 toxicosis. To avoid being faced with such a therapeutic dilemma, we suggest that reproductive-age female patients who present with large goitre and very high TSI levels leading to T3-predominant Graves' hyperthyroidism, should undergo early definitive therapy by total thyroidectomy followed by L-thyroxine replacement, before trying to conceive. They should also be advised to take appropriate contraceptive measures before definitive surgical therapy.

Greater than $99.9 \%$ of circulating T4 is protein-bound. When preoperative total T4 was very low at $9 \mathrm{nM}(70-140)$, starting our patient on daily maintenance doses of 75-100 mcg L-T4 after total thyroidectomy would have meant a slow correction of fT4, as binding sites on thyroxinebinding globulin, transthyretin and albumin are being saturated. Extrapolating from early clinical studies of patients with myxoedema coma where the mean thyroxine deficit was estimated at $360 \mathrm{mcg}$, and assuming an euthyroid daily T4 turnover of $80 \mathrm{mcg}$, a daily maintenance dose of $100 \mathrm{mcg}$ would take about 18 days to replete the extrathyroidal T4 pool. ${ }^{17}$ A study by Arlot et al., showed that patients with myxoedema coma who were loaded with oral L-T4 500 mcg followed by 100 ug daily, did not achieve normal total T3 nor normal total T4 blood levels within 14 days. ${ }^{18}$ In contrast, Ridgway et al., showed that in 7 non-comatose hypothyroid patients with mean total T4 $11.6 \mathrm{nM}$ (51-141), given IV L-T4 at mean loading dose of $428 \mathrm{mcg}$ and then $100 \mathrm{mcg}$ daily, total T4 levels were normalized within 24 hours, as in our case. ${ }^{19}$

Unlike the case studies mentioned above, our patient was clinically euthyroid preoperatively, with normal T3 levels. However, her TSH had risen over 16 days from $3.37 \mathrm{mIU} / \mathrm{L}$ to $17.0 \mathrm{mIU} / \mathrm{L}$ at 24 -hours before surgery, i.e., classic primary hypothyroid pattern. We were concerned that starting with the usual daily maintenance L-T4 dose and the consequent slow correction of T4 would adversely affect her postoperative recovery. Thyroid cancer patients who were rendered short-term hypothyroid by withdrawing both L-T4 and L-T3 therapy for 2-3 weeks were shown to have normal baseline minute ventilation, but depressed hypoxic ${ }^{20}$ and hypercarbic ${ }^{21}$ ventilatory drives that normalized after resuming thyroid hormone replacement therapy. There was also a potential risk of depressed cardiac function and increased systemic vascular resistance post-thyroidectomy. ${ }^{22}$ Hence, we opted to administer an intravenous loading dose of L-T4, with no risk of aspiration, to quickly replete extrathyroidal T4 pool, and thereby allow maintenance of adequate T3 levels by peripheral conversion as calorie intake resumed to normal postoperatively (Figure 2).

As our patient was clinically euthyroid preoperatively, with normal T3 levels, another option would have been to give a loading dose of oral L-T4 after full recovery from anaesthesia. It has been shown that within 2 to 3 hours of oral ingestion of either a weight-based ${ }^{23}$ or 1000

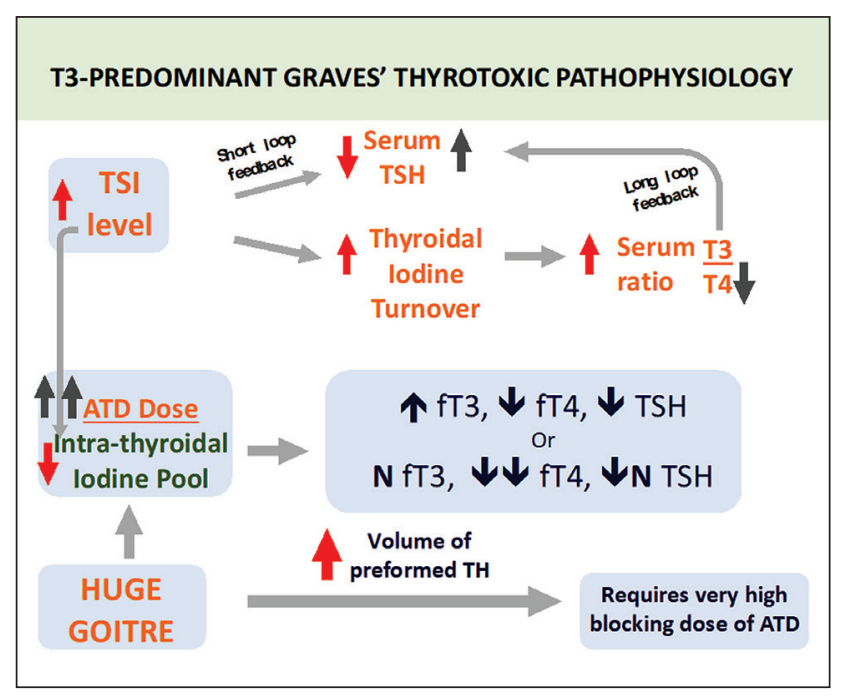

Figure 3. Proposed pathophysiology of T3-predominant Graves' thyrotoxicosis with discordant thyroid function.

$\mathrm{mcg}^{24}$ of L-T4, significant rises of fT4 to adequate levels may be attained. This is seen in a test setting to rule out malabsorption in patients with medication nonadherence who remain biochemically hypothyroid despite "taking" high doses of L-T4. Moreover, Rajendran et al., have described their institutional experience of successfully treating 13 out of 14 patients with myxoedema coma using oral L-T4 loading therapy. ${ }^{25}$

Our patient was young with no history of cardiovascular diseases nor arrhythmias. If our patient was elderly or with heart disease, one would be more circumspect about LT4 loading, to avoid precipitation of myocardial ischemia and cardiac failure. Although total thyroidectomy would have removed our patient's thyroidal source of T3, we did not start the patient on liothyronine as she was well preoperatively and we did not expect any postoperative complications nor prolonged reduced calorie intake that might impair peripheral T4 to T3 conversion.

The pathophysiology of T3-predominant Graves' thyrotoxicosis, including how a very high TSI level possibly suppresses TSH in a short feedback loop that leads to discordant thyroid function, is illustrated in Figure 3.

\section{CONCLUSION}

This case exemplifies how patients with T3-predominant Graves' hyperthyroidism characterised by markedly elevated serum thyroid stimulating immunoglobulin (TSI) levels and large goitre may display hypertriiodothyroninemia followed by eutriiodothyroninemia with discordant and severe hypothyroxinemia, as ATD therapy is titrated. For the ensuing severe preoperative hypothyroxinemia, we believe this is the first case report demonstrating its safe correction with intravenous levothyroxine loading therapy immediately following total thyroidectomy.

Ethical Consideration

Patient consent was obtained before submission of the manuscript.

Statement of Authorship

All authors certified fulfilment of ICMJE authorship criteria. 


\section{Author Disclosure}

The authors declared no conflict of interest.

\section{Funding Source}

None.

\section{References}

1. Takamatsu J, Sugawara M, Kuma K, et al. Ratio of serum triiodothyronine to thyroxine and the prognosis of triiodothyroninepredominant Graves' disease. Ann Intern Med 1984;100(3):372-5. PMID: 6546484. https;//doi.org/10.7326/0003-4819-100-3-372.

2. Chen JJ, Ladenson PW. Discordant hypothyroxinemia and hypertriiodothyroninemia in treated patients with hyperthyroid Graves' disease. J Clin Endocrinol Metab. 1986;63(1):102-6. PMID: 2423547. https://doi.org/10.1210/jcem-63-1-102.

3. Takamatsu J, Hosoya T, Naito N, et al. Enhanced thyroid iodine metabolism in patients with triiodothyronine-predominant Graves' disease. J Clin Endocrinol Metab. 1988;66(1):147-52. PMID: 3335601. https://doi.org/10.1210/jcem-66-1-147.

4. Larsen PR. Thyroidal triiodothyronine and thyroxine in Graves' disease: Correlation with presurgical treatment, thyroid status, and iodine content. J Clin Endocrinol Metab. 1975;41(06):1098-104. PMID: 54364. https://doi.org/10.1210/jcem-41-6-1098.

5. Laurberg $\mathrm{P}$, Vestergaard $\mathrm{H}$, Nielsen $\mathrm{S}$, et al. Sources of circulating 3,5,3'-triiodothyronine in hyperthyroidism estimated after blocking of type 1 and type 2 iodothyronine deiodinases. J Clin Endocrinol Metab. 2007;92(6):2149-56. PMID: 17389703. https://doi.org/10.1210/ jc.2007-0178

6. Dalan R, Kon W, Phenotypic expression and challenges of a distinct form of thyrotoxicosis: Triiodothyronine-predominant Graves' disease - aggressive, refractory, and anything but banal. Endocrinologist. 2008;18(2):90-4. ScholarBank@NUS Repository.https://doi.org/10.1097/ TEN.0b013e3181693d5e.

7. Gereben B, McAninch EA, Ribeiro MO, Bianco AC. Scope and limitations of iodothyronine deiodnases in hypothyroidism. Nat Rev Endocrinol. 2015;11(11):642-52. PMID: 26416219. PMCID: PMC5003781. https://doi.org/10.1038/nrendo.2015.155.

8. Gereben B, Zavacki AM, Ribich S, et al. Cellular and molecular basis of deiodinase-regulated thyroid hormone signaling. Endocr Rev. 2008;29(7):898-938. PMID: 18815314. PMCID: PMC2647704. https:// doi.org/10.1210/er.2008-0019.

9. Christoffolete MA, Ribeiro R, Singru P, et al. Atypical expression of type 2 iodothyronine deiodinase in thyrotrophs explains the thyroxine-mediated pituitary thyrotropin feedback mechanism. Endocrinology. 2006;147(4):1735-43. PMID: 16396983. https;//doi.org/ 10.1210/en.2005-1300.

10. Prummel MF, Brokken LJS, Wiersinga WM. Ultra-short-loop feedback of thyrotropin secretion. Thyroid. 2004;14(10):825-9. PMID: 15588378. https://doi.org/10.1089/thy.2004.14.825.

11. Brokken LJS, Scheenhart JWC, Wiersinga WM, Prummel MF. Suppression of serum TSH by Graves' Ig: Evidence for a functional pituitary TSH receptor. J Clin Endocrinol Metab. 2001;86(10):4814-7. PMID: 11600546. https://doi.org/10.1210/jcem.86.10.7922.

12. Prummel MF, Brokken LJ, Meduri G, Misrahi M, Bakker O, Wiersinga WM. Expression of the thyroid-stimulating hormone receptor in the folliculo-stellate cells of the human anterior pituitary. J Clin Endocrinol Metab. 2000; 85(11):4347-53. PMID: 11095478. https://doi. org/10.1210/jcem.85.11.6991.
13. Chung YJ, Lee BW, Kim JY, et al. Continued suppression of serum TSH level may be attributed to TSH receptor antibody activity as well as the severity of thyrotoxicosis and the time to recovery of thyroid hormone in treated euthyroid Graves' patients. Thyroid. 2006;16(12): 1251-7. PMID: 17199435. https://doi.org/10.1089/thy.2006.16.1251.

14. Pedraza PE, Obregon MJ, Escobar-Morreale HF, Escobar del Rey F, Morreale de Escobar G. Mechanisms of adaptation to iodine deficiency in rats: Thyroid status is tissue specific. Its relevance for man. Endocrinology. 2006; 147(5):2098-108. PMID: 16455775. https:// doi.org/10.1210/en.2005-1325.

15. Fonseca TL, Correa-Media M, Campos MPO, et al. Coordination of hypothalamic and pituitary T3 production regulates TSH expression. J Clin Invest 2013;123(4):1492-500. PMID: 23524969. PMCID: PMC3613903. https://doi.org/10.1172/JCI61231.

16. Alexander EK, Pearce EN, Brent GA, et al. 2017 Guidelines of the American Thyroid Association for the diagnosis and management of thyroid disease during pregnancy and the postpartum. Thyroid 2017;27(3):315-89. PMID: 28056690. https://doi.org/10.1089/ thy.2016.0457.

17. Holvey DN, Goodner CJ, Nicoloff JT, Dowling JT. Treatment of myxoedema coma with intravenous thyroxine. Arch Int Med. 1964;113:89-96. PMID: 14067598. https://doi.org/10.1001/archinte. 1964.00280070091015.

18. Arlot S, Debussche X, Lalau JD, et al. Myxoedema coma: Response of thyroid hormones with oral and intravenous high-dose L-thyroxine treatment. Intensive Care Med. 1991;17(1):16-8. PMID: 2037720. https://doi.org/10.1007/BF01708403.

19. Ridgway EC, McCammon JA, Benotti J, Maloof F. Acute metabolic responses in myxoedema to large doses if intravenous L-thyroxine. Ann Int Med. 1972:77(4):549-55. PMID: 4642735. https://doi.org/ 10.7326/0003-4819-77-4-549.

20. Zwillich CW, Pierson DJ, Hofeldt FD, Lufkin EG, Weil JV. Ventilatory control in myxedema and hypothyroidism. N Engl J Med. 1975;292(1):662-5. PMID: 1113761. https://doi.org/10.1056/ NEJM197503272921302.

21. Ambrosino N, Pacini F, Paggiaro PL, et al. Impaired ventilatory drive in short-term primary hypothyroidism and its reversal by L-triiodothyronine. J Endocrinol Invest. 1985;8(6):533-6. PMID 3833897. https://doi.org/10.1007/BF03348555.

22. Kohl B, Schwartz S. Surgery in the patient with endocrine dysfunction. Anesthesiology Clin. 2009;27(4):687-703. PMID: 19942174, https:// doi.org/10.1016/j.anclin.2009.09.005.

23. Walker JN, Shillo P, Ibbotson $\mathrm{V}$, et al. A thyroxine absorption test followed by weekly thyroxine administration: A method to assess nonadherence to treatment. Eur J Endocrinol. 2013;168(6):913-7. PMID 23554450. https://doi.org/10.1530/EJE-12-1035.

24. Balla M, Jhingan RM, Rubin DJ. Rapid levothyroxine absorption testing: A case series of nonadherent patients. Int J Endocrinol Metab. 2015;13(4):e31051. PMID: 26633982. PMCID: PMC4659333. https://doi.org/10.5812/ijem.31051.

25. Rajendran A, Bhavani N, Nair V, Pavithran PV, Menon VU, Kumar H. Oral levothyroxine is an effective option for myxoedema coma: A single centre experience. Eur Thyroid J. 2021;10(1):52-8. PMID: 33777819. PMCID: PMC7983610 (available on 2021-09-01). https://doi.org/10.1159/000507855.

Authors are required to accomplish, sign and submit scanned copies of the JAFES Author Form consisting of: (1) Authorship Certification, that authors contributed substantially to the work, that the manuscript has been read and approved by all authors, and that the requirements for authorship have been met by each author; (2) the Author Declaration, that the article represents original material that is not being considered for publication or has not been published or accepted for publication elsewhere, that the article does not infringe or violate any copvrights or intellectual property rights, and that no references have been made to predatory/suspected predatory journals; (3) the Author Contribution Disclosure, which lists the specific contributions of authors; (4) the Author Publishing Agreement which retain author copyright, grants publishing and distribution rights to JAFES, and allows JAFES to apply and enforce an Attribution-Non-Commercial Creative Commons user license; and (5) the Conversion to Visual Abstracts (*optional for original articles only) to improve dissemination to practitioners and lay readers Authors are also required to accomplish, sign, and submit the signed ICMJE form for Disclosure of Potential Conflicts of Interest. For original articles, authors are required to submit a scanned copy of the Ethics Review Approval of their research as well as registration in trial registries as appropriate. For manuscripts reporting data from studies involving animals, authors are required to submit a scanned copy of the Institutional Animal Care and Use Committee approval. For Case Reports or Series, and Images in Endocrinology, consent forms, are required for the publication of information about patients; otherwise, appropriate ethical clearance has been obtained from the institutional review board. Articles and any other material published in the JAFES represent the work of the author(s) and should not be construed to reflect the opinions of the Editors or the Publisher. 